Check for updates

Cite this: RSC Adv., 2019, 9, 13896

Received 20th February 2019

Accepted 26th April 2019

DOI: 10.1039/c9ra01277j

rsc.li/rsc-advances

\section{Synthesis and antiproliferative assay of triazolyl- 2,2-dimethyl-3-phenylpropanoates as potential HDAC inhibitors}

\author{
Samir El-Rayes, (D) *a Gomaa M. S., ${ }^{\text {b }}$ Abouelmagd A., (D) a Walid Fathalla (D) ${ }^{c}$ \\ and Ibrahim. A. I. Ali ${ }^{a}$
}

Recently, histone deacetylase (HDAC) inhibition has gained great importance in cancer treatment. We herein, describe the design, synthesis and biological testing of 16 compounds based on the structure modification of methyl 3-(4-(2-chloroacetamido)phenyl)-3-hydroxy-2,2-dimethylpropanoate (5) and methyl 3-(4-chlorophenyl)-3-hydroxy-2,2-dimethylpropanoate (14) as potent HDACls. Two series were synthesized based on the structure of 3-(4-(2-chloroacetamido)phenyl)-3-hydroxy-2,2dimethylpropanoate and 3-(4-chlorophenyl)-3-hydroxy-2,2-dimethylpropanoate. The compounds were tested in vitro for their antiproliferative activity against HeLa cells. The results identified compounds $16 \mathrm{~b}$, 16c, 18 (IC $50 ; 11.69,0.69,3.39 \mu \mathrm{M}$ respectively) as potential good inhibitors compared to the standard drug doxorubicin $\left(\mathrm{IC}_{50} ; 2.29 \mu \mathrm{M}\right)$. Those compounds also exhibited promising activity against other cancer cell lines namely; HCT-116, MCF-7, PC3, A549 and therefore were selected as hits for further optimization. The docking experiment results performed on the HDAC-2 crystal structure were in close agreement with the biological testing results which suggest that those compounds potentially work through HDAC inhibition.

\section{Introduction}

Cancer is one of the major health challenges worldwide. Cancer is an abnormal cell growth that shifts the controlled mechanisms of cell proliferation and differentiation associated with high mortality rate. ${ }^{1}$ Chemotherapy is one of the most effective approaches used to treat solid as well as hematological tumors. ${ }^{2,3}$ Quinazoline sulfonamide and quinazolindione $\mathrm{e}^{4,5}$ are well established privileged structures in cancer chemotherapy that showed great activity against different types of cancer including breast cancer and pancreatic cancer. Acetylation of histones in a eukaryotic cell is involved in many cellular functions including proliferation, cell-cycle regulation and apoptosis. ${ }^{6}$ Histone acetylation is controlled by a balance between histone acetyl transferases (HATs) (associated with gene transcription) and histone deacetylase (HDAC) involved in deacetylation of $\varepsilon$-amino groups of lysine residue on histone tails (associated with gene silencing). ${ }^{7}$ Abnormal alterations in the histone

${ }^{a}$ Department of Chemistry, Faculty of Science, Suez Canal University, Ismailia, Egypt. E-mail: samir_elrayes@yahoo.com

${ }^{b}$ Department of Pharmaceutical Chemistry, College of Clinical Pharmacy, Imam Abdulrahman Bin Faisal University, P. O. Box 1982, Dammam 31441, Eastern Province, Kingdom of Saudi Arabia

${ }^{c}$ Department of Physics and Math., Faculty of Engineering, Port-Said University, PortSaid, Egypt acetylation process are associated with cancer development. ${ }^{8}$ Therefore, histone deacetylase (HDAC) inhibition is considered one of the promising strategies for the development of novel anticancer agents. ${ }^{9}$ HDACIs are classified into different classes depending on their structures namely aliphatic acids, hydroxamic acids, 2-aminoanilides, cyclic peptides, and electrophilic ketones. ${ }^{10}$ In general, most of the currently reported HDACIs consist of a zinc-binding group (ZBG) and a five- to six-carbon hydrophobic spacer attached to a hydrophobic group via a connection unit (Fig. 1a). ${ }^{11}$

Until now, four HDACIs are approved for cancer treatment including three synthetic hydroxamate HDACIs (SAHA, Belinostat PXD 101, and Panobinostat) and one natural product cyclic depsipeptide (romidepsin). ${ }^{12}$ Other compounds in clinical trials include hydroxamic acid derivatives such as panobinostat (LBH589) and pracinostat (SB-939) with an $N$-hydroxyacrylamide moiety exhibiting excellent HDAC inhibitory activity ${ }^{13,14}$ and benzamides such as entinostat (MS-275) and mocetinostat (MGCD-0103). ${ }^{15,16}$ Therefore, developing and identification of potent HDACIs is a promising therapeutic strategy in cancer treatment.

Our proposed HDAC inhibitors were designed to combine the most important structural features reported for HDAC in a simple chemical structure (Fig. 1b). The compounds contain a sterically hindered amide, ester or hydroxamate on one side of the molecule. A triazole moiety was incorporated for steric effect 
(a)

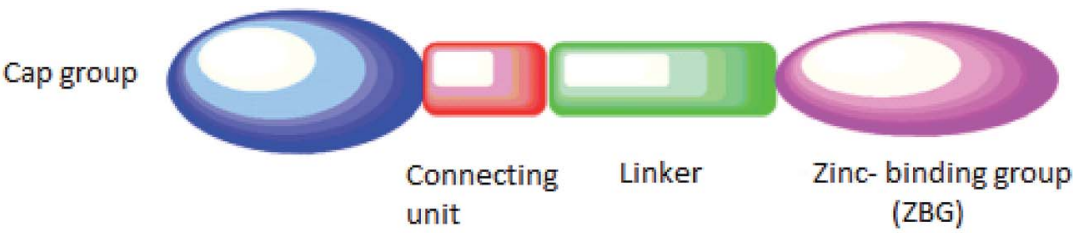<smiles>O=C(C=Cc1cccc(S(=O)(=O)Nc2ccccc2)c1)NO</smiles>

SAHA, Vorinostat

Belinostat PXD 101<smiles>Nc1ccccc1NC(=O)c1ccc(CNC(=O)OCc2cccnc2)cc1</smiles>

(b)

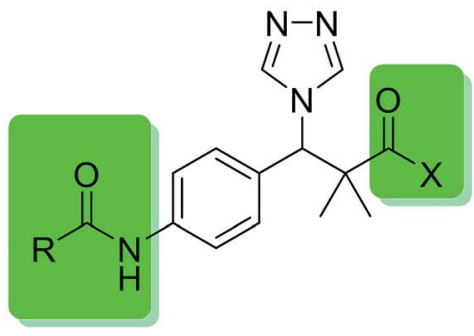

Fig. 1 (a) Classical histone deacetylase (HDAC) inhibitors. (b) Structure design of our proposed HDAC inhibitors.

as well as to optimize the binding interaction and improve the pharmacokinetic properties. A central aromatic ring connects the amide group with another acetamide moiety to mimic the well-known benzamide inhibitors.

\section{Discussion}

We now report the synthesis of the targeted structures; $N$ hydroxy-2,2-dimethyl-3-(4-(2-(phenylamino)acetamido)phenyl)3-(4H-1,2,4-triazol-4-yl)propanamide (8), N-hydroxy-3-(4-(2-((2(hydroxyamino)-2-oxoethyl)amino)acetamido)phenyl)-2,2-dimet thyl-3-(4H-1,2,4-riazol-4-yl)propanamide (11) and their analogues 16a-d, 18 as HDAC inhibitors.

Methyl 3-hydroxy-2,2-dimethyl-3-(4-nitrophenyl)propanoate (3) was prepared by the reaction of 4-nitrobenzaldehyde 1 with trimethylsilyl ketene acetal 2 in the presence of pyridine- $N$ oxide and $\mathrm{LiCl}$ in DMF at room temperature under nitrogen atmosphere to afford the ester 3 in $69 \%$ yield. ${ }^{17,18}$ Reduction of 3 by using hydrogen atmosphere in the presence of $\mathrm{Pd} / \mathrm{C}$ catalyst in ethanol at room temperature for $3 \mathrm{~h}$ afforded the desired ester 4 in $87 \%$ yield. The acylation reaction of the ester 4 with chloroacetyl chloride in the presence of triethyl amine and catalytic amount of DMAP in dichloromethane for $12 \mathrm{~h}$.
Afforded methyl 3-(4-(2-chloroacetamido)phenyl)-3-hydroxy2,2-dimethylpropanoate 5 in $70 \%$ yield, scheme 1.

Structure modification of chloroacetamido derivative 5 could simply be achieved by the reaction with nucleophiles and the attachment of triazole moiety to produce both targeted structures $\mathrm{N}$-hydroxy-2,2-dimethyl-3-(4-(2-(phenylamino)acetamido) phenyl)-3-(4H-1,2,4-triazol-4-yl)propanamide (8) and $N$-hydroxy3-(4-(2-((2-(hydroxyamino)-2-oxoethyl)amino)acetamido)phenyl) -2,2-dimethyl-3-(4H-1,2,4-triazol-4-yl)propanamide (11). Thus, the reaction of chloroacetamide derivative $\mathbf{5}$ with aniline in pyridine under reflux condition for $10 \mathrm{~h}$. Afforded methyl 3hydroxy-2,2-dimethyl-3-(4-(2-(phenylamino)acetamido)phenyl) propanoate (6) in $84 \%$ yield. Successful attachment of triazole residue was achieved by the reaction of 6 with triazole in the presence of CDI in acetonitrile under reflux condition for $48 \mathrm{~h}$. To afford the triazole derivative 7 in $67 \%$ yield. The first targeted compound $\quad N$-hydroxy-2,2-dimethyl-3-(4-(2-(phenylamino)acetamido)phenyl)-3-(4H-1,2,4-triazol-4-yl)propanamide (8) was finally produced in $58 \%$ yield by the reaction of 7 with hydroxyl amine hydrochloride in the presence of $\mathrm{KOH}$ in ethanol under reflux condition, Scheme 2 .

Similarly, the second targeted molecule $N$-hydroxy-3-(4-(2-((2(hydroxyamino)-2-oxoethyl)amino)acetamido)phenyl)-2,2- 
<smiles>COC(=O)C(C)(C)C(O)c1ccc([N+](=O)[O-])cc1</smiles><smiles>COC(=O)C(C)(C)C(O)c1ccc(NC(=O)CCl)cc1</smiles><smiles>COC(=O)C(C)(C)C(O)c1ccc(N)cc1</smiles>

Scheme 1 Sequential synthesis of methyl 3-(4-(2-chloroacetamido)phenyl)-3-hydroxy-2,2-dimethylpropanoate 5.

dimethyl-3-(4H-1,2,4-triazol-4-yl)propan-amide (11) is prepared from chloroacetamido derivative $\mathbf{5}$ via three step sequential reactions. Thus, 5 reacted with glycine methyl ester hydrochloride in pyridine under reflux condition for $10 \mathrm{~h}$. Afforded methyl 3-hydroxy-3-(4-(2-((2-methoxy-2-oxoethyl)amino)acetamido) phenyl)-2,2-dimethylpropanoate (9) in $71 \%$ yield. Next, the reaction of 9 with triazole in the presence of CDI in acetonitrile under reflux condition for $48 \mathrm{~h}$. Afforded 10 in $71 \%$ yield and finally 11 was produced in $74 \%$ yield by the reaction of 10 with hydroxyl amine hydrochloride in the presence of $\mathrm{KOH}$ in ethanol under reflux condition, Scheme 3.

The structure assignment of both targeted structures $\mathrm{N}$ hydroxy-2,2-dimethyl-3-(4-(2-(phenylamino)acetamido)phenyl)3-(4H-1,2,4-triazol-4-yl)propanamide (8) and $\mathrm{N}$-hydroxy-3-(4-(2((2-(hydroxyamino)-2-oxoethyl)amino)acetamido)phenyl)-2,2dimethyl-3-(4H-1,2,4-triazol-4-yl)propanamide (11) is based on ${ }^{1} \mathrm{H}$ and ${ }^{13} \mathrm{C}$ NMR spectroscopy and physicochemical analysis. Thus, the ${ }^{1} \mathrm{H}$ NMR spectrum of $\mathbf{1 1}$ exhibit signals at $\delta 6.10$ and $9.00 \mathrm{ppm}$ are typically associated with two $\mathrm{NH}$ groups. The ${ }^{1} \mathrm{H}$ NMR spectrum also presented an important signal at $10.15 \mathrm{ppm}$ that is typically associated with $2 \mathrm{OH}$ oximes. The ${ }^{13} \mathrm{C}$ NMR spectrum displayed signals at $\delta=49.4$, 52.0, 173.8 and $174.9 \mathrm{ppm}$, associated with two $\mathrm{CH}_{2}$ and $2 \mathrm{CO}$ groups, respectively (Fig. 2).

Our next target was the preparation of a number of 3-(4-chlorophenyl)- $N$-arylidene-2,2-dimethylpropanehydrazide 16a-d and $N$ benzyl-3-(4-chlorophenyl)-3-hydroxy-2,2-dimethylpropanamide (18) as structure analogues of compounds $\mathbf{8}$ and $\mathbf{1 1}$ for the CYP26 inhibitors evaluation. The reaction of 4-chlorobenzaldehyde (12) with methyl 2-bromo-2-methylpropanoate (13) in benzene under reflux condition afforded 3-(4-chlorophenyl)-3-hydroxy2,2-dimethylpropanoate (14) in $79 \%$ yield. Hydrazinolysis of ester 14 afforded the hydrazide 15. The reaction of hydrazide with aldehyde in ethanol under reflux condition for $6 \mathrm{~h}$. Afforded the hydrazone 16a-d, Scheme 4.

On the other hand, the hydrazide reacted with benzyl amine under azide coupling condition to afford $\mathrm{N}$-benzyl-3-(4-<smiles>COC(=O)C(C)(C)C(O)c1ccc(NC(=O)CCl)cc1</smiles>

5<smiles>CC(C)(C(=O)NO)C(c1ccc(NC(=O)CNc2ccccc2)cc1)n1cnnc1</smiles>
8<smiles>COC(=O)C(C)(C)C(O)c1ccc(NC(=O)CNc2ccccc2)cc1</smiles><smiles>COC(=O)C(C)(C)C(c1ccc(NC(=O)CNc2ccccc2)cc1)n1cnnc1</smiles>

Scheme 2 Sequential synthesis of the targeted molecule $\mathrm{N}$-hydroxy-2,2-dimethyl-3-(4-(2-(phenylamino)acetamido)phenyl)-3-(4H-1,2,4-triazol-4-yl)propanamide (8). 
<smiles>COC(=O)C(C)(C)C(O)c1ccc(NC(=O)CCl)cc1</smiles>

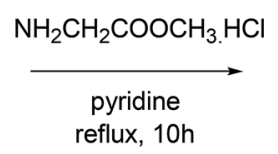

reflux, $10 \mathrm{~h}$<smiles>COC(=O)CNCC(=O)Nc1ccc(C(O)C(C)(C)C(=O)OC)cc1</smiles>

9

acetonitrile triazole<smiles>CC(C)(C(=O)NO)C(c1ccc(NC(=O)CNCC(=O)NO)cc1)n1cnnc1</smiles>

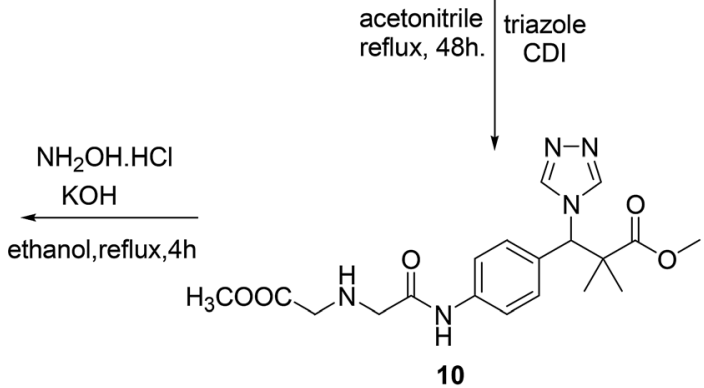

Scheme 3 Sequential synthesis of the targeted molecule $\mathrm{N}$-hydroxy-3-(4-(2-((2-(hydroxyamino)-2-oxoethyl)amino)acetamido)phenyl)-2,2dimethyl-3-(4H-1,2,4-triazol-4-yl)propanamide (11).

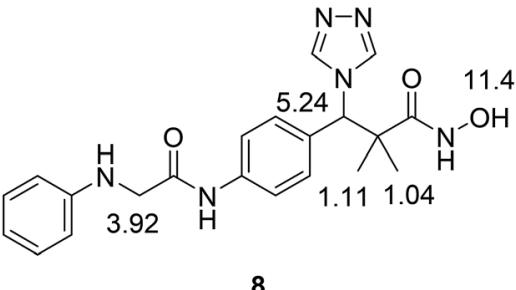

8

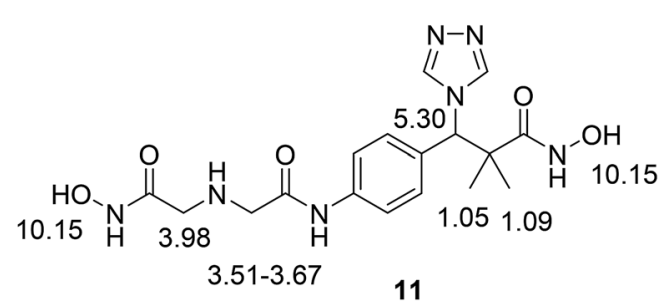

11

Fig. 2 Selected ${ }^{1} \mathrm{H}$ and ${ }^{13} \mathrm{C}$ NMR spectral data of $\mathrm{N}$-hydroxy-2,2-dimethyl-3-(4-(2-(phenylamino)acetamido)phenyl)-3-(4H-1,2,4-triazol-4-yl) propanamide (8) and N-hydroxy-3-(4-(2-((2-(hydroxyamino)-2-oxoethyl)amino)acetamido)phenyl)-2,2-dimethyl-3-(4H-1,2,4-triazol-4-yl) propanamide (11).

chlorophenyl)-3-hydroxy-2,2-dimethylpropanamide (18) in 77\% yield, Scheme 5.

The structure assignment of 3-(4-chlorophenyl)- $\mathrm{N}$-arylidene2,2-dimethylpropanehydrazide 16a-d and N-benzyl-3-(4chlorophenyl)-3-hydroxy-2,2-dimethylpropanamide (18) is based on ${ }^{1} \mathrm{H}$ and ${ }^{13} \mathrm{C}$ NMR spectroscopy and physicochemical analysis. Thus, the ${ }^{1} \mathrm{H}$ NMR spectrum of 16a showed newly introduced salicylaldehyde signals at 8.59 and 11.40 for $\mathrm{CH}=$ and $\mathrm{OH}$ groups. $N$-Benzyl-3-(4-chlorophenyl)-3-hydroxy-2,2dimethylpropanamide (18) was identified by ${ }^{1} \mathrm{H}$ and ${ }^{13} \mathrm{C}$ NMR spectroscopy. The ${ }^{1} \mathrm{H}$ NMR spectrum showed newly introduced benzyl group signals at 4.35 and 6.08 for $\mathrm{CH}_{2}$ and $\mathrm{NH}$ groups. The ${ }^{13} \mathrm{C}$ NMR spectrum displays signals at 46.2 corresponding to $\mathrm{CH}_{2}$ group.

The cytotoxicity of each compound was investigated against different cancer cell lines namely; HCT-116, MCF-7, PC3, A549 at concentrations $(0.1,1,10$, and $100 \mu \mathrm{M})$ using MTT assay colorimetric assay. Data illustrated in (Table 1) shows the percentage of viability of HCT-116 cells after $48 \mathrm{~h}$ from treatment with different concentrations of the compounds versus control. The results revealed that the compound $\mathbf{1 6 c}$ had the lowest $\mathrm{IC}_{50}$ value $(0.69 \mu \mathrm{M})$, followed by compounds $16 \mathbf{b}$ and $\mathbf{1 8}$ with $\mathrm{IC}_{50}$ values equal $11.6 \mu \mathrm{M}, 3.39 \mu \mathrm{M}$, respectively compared to the standard drug doxorubicin $\left(\mathrm{IC}_{50} ; 2.29 \mu \mathrm{M}\right)$ (Table 2).
Interestingly, the results of the different concentrations antiproliferative assay conducted on other cancer cell lines were consistent with the HeLa cells results, with compounds $\mathbf{1 6 b}$, $16 c, 18$ on top of the activity list and also showing close activity to the standard drugs doxorubicin and 5-fluoro uracil (Tables 36).

The accurate $\mathrm{IC}_{50}$ results on A549 cells again proved compounds $16 \mathbf{b}$ and $16 \mathbf{c}$ as superior antiproliferative agents with $\mathrm{IC}_{50}$ equal to $79.4 \mu \mathrm{M}$ and $85.1 \mu \mathrm{M}$ respectively compared to an $\mathrm{IC}_{50}$ of $72.4 \mu \mathrm{M}$ for the standard drug 5 -fluoro uracil.

The consistent comparable activity of compounds $\mathbf{1 6 b}$ and 16c on all tested cell lines suggested that the triazole ring is not of great importance compared to the hydroxyl group. Moreover, shifting the benzyl amide group next to the hydroxy isobutyl group resulted in a highly active compound (compound 18) possibly due to an increase in the stabilization of the amide bond that is essential for HDAC inhibition. Surprisingly, compound 18 although is the most different in structure among the designed and synthesized compounds as it lacks the triazole, the ester or the hydroxamic acid groups and the benzamide substituents, is one of the most active compounds against almost all tested cancer cell lines. This implies that for our compounds the structurally hindered hydroxyisobutyl acetamide is more important than the benzamide and the hydroxamate moieties. Therefore, compound $\mathbf{1 8}$ is considered as 


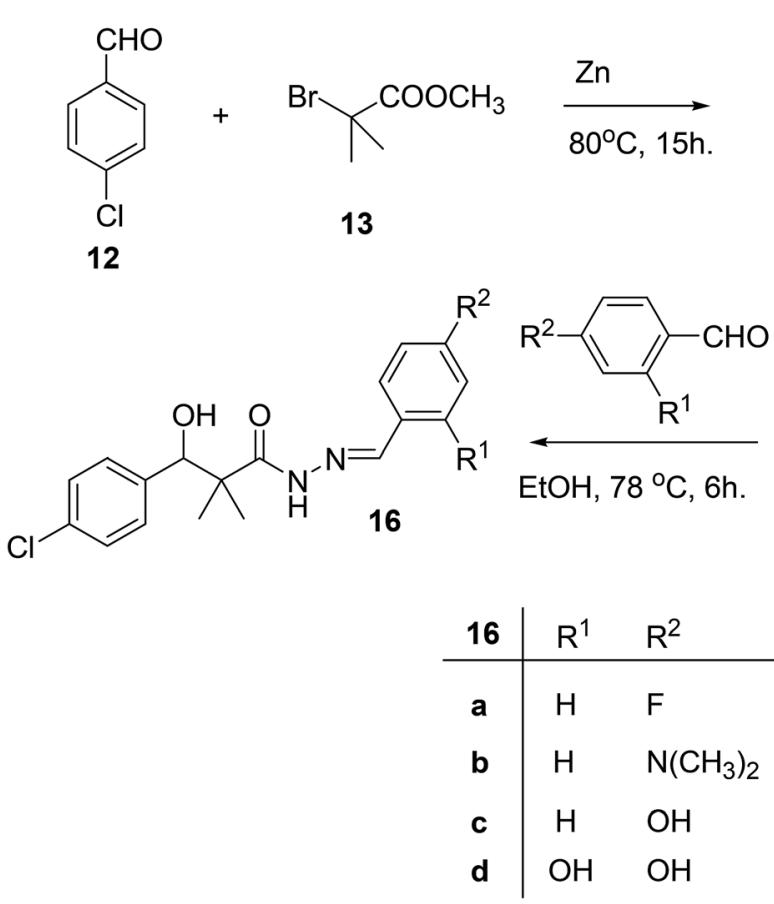<smiles>COC(=O)C(C)(C)C(O)c1ccc(Cl)cc1</smiles>

Scheme 4 Sequential synthesis of 3-(4-chlorophenyl)- $N$-arylidene-2,2-dimethylpropanehydrazide 16a-d.

a potential lead for further optimization and development followed by compounds $16 \mathrm{~b}$ and $16 \mathrm{c}$ which are basically aminohydrazone derivatives of compound $\mathbf{1 8}$ (Table 7).

The activity of the docked compounds was investigated by comparison of their ligand-receptor interactions with the amino acids of the receptor binding site. As shown in Table 8 and Fig. 3, the original ligand forms three hydrogen bonds with Tyr 308, His145, and Gly154. Moreover, it forms two van der Waals interactions with His 183 and Phe 155. Compound 15 forms six hydrogen bonds with Tyr 308, Asp 269, His 183, His 145 and Asp 181, and it forms one van der Waals interaction with Arg 39. Compound 16a forms three hydrogen bonds with His 145 and His 183, and it forms two van der Waals interactions with Phe 155 and Arg 39. Compound 16b forms five hydrogen bonds with Tyr 308, Asp 269, His 146, Asp 181 and His 145 , and it forms three van der Waals interactions with Phe 155,
His 183 and Arg 39. Compound 16c forms three hydrogen bonds with Ala 141 and Gly 154, and it forms two van der Waals interactions with Phe 155 and His 183. Compound 16d forms three hydrogen bonds with Asp 104, Asp 269, and Tyr 308 and it forms two van der Waals interactions with His 145 and Gly 154 . Compound 18 forms four hydrogen bonds with Gly 154, Tyr 308, His 146 and His 145, and it forms two van der Waals interactions with Phe 155 and Arg 39.

From the above discussion, compound $\mathbf{1 8}$ is the only compound that was able to bind the three key residues that are involved in binding the co-crystallized ligand through hydrogen bonding namely; His 145, Gly 154, and Tyr 308. Compound 16B formed hydrogen bonding with only two of the key residues namely; His 145, and Tyr 308. This is in close agreement with the antiproliferative assay results that identified compounds $\mathbf{1 8}$, 16B, 16C as the most active compounds. Therefore, based on<smiles>CCO[N+](=O)[N+](C)=O</smiles>

15<smiles>CC(C)(C(=O)NCc1ccccc1)C(O)c1ccc(Cl)cc1</smiles>

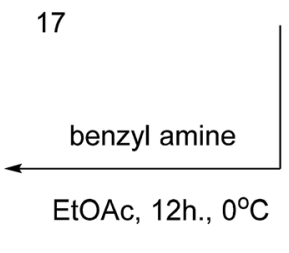

18

Scheme 5 Sequential synthesis of N-benzyl-3-(4-chlorophenyl)-3-hydroxy-2,2-dimethylpropanamide (18). 
Table 1 Anticancer activity of tested compounds against HeLa cells

$\%$ of cell growth treated with different (conc. $\mu \mathrm{M} \pm \mathrm{SEM}$ ) of cpds.

\begin{tabular}{lllcl} 
Cpds. & 0.1 & 1 & 10 & 100 \\
\hline $\mathbf{3}$ & 61.47361 & 64.73607 & 64.99267 & 48.42375 \\
$\mathbf{4}$ & 57.14809 & 61.58358 & 51.6129 & 44.17155 \\
$\mathbf{5}$ & 79.98534 & 90.72581 & 100.2933 & 71.66422 \\
$\mathbf{6}$ & 62.86657 & 68.58504 & 75.80645 & 50.62317 \\
$\mathbf{7}$ & 94.72141 & 86.91349 & 70.96774 & 49.41349 \\
$\mathbf{8}$ & 54.80205 & 54.72874 & 59.12757 & 49.81672 \\
$\mathbf{9}$ & 64.03959 & 73.05718 & 62.79326 & 49.59677 \\
$\mathbf{1 0}$ & 94.72141 & 86.91349 & 70.96774 & 49.41349 \\
$\mathbf{1 1}$ & 92.33871 & 93.8783 & 86.36364 & 48.86364 \\
$\mathbf{1 4}$ & 79.98534 & 90.72581 & 100.2933 & 71.66422 \\
$\mathbf{1 5}$ & 62.86657 & 68.58504 & 75.80645 & 50.62317 \\
$\mathbf{1 6 a}$ & 65.9824 & 61.10704 & 58.5044 & 50.73314 \\
$\mathbf{1 6 b}$ & 51.46628 & 53.07918 & 50.18328 & 47.83724 \\
$\mathbf{1 6 c}$ & 52.84311 & 49.85924 & 51.64956 & 53.00587 \\
$\mathbf{1 6 d}$ & 67.88757 & 63.57404 & 71.86435 & 50.3476 \\
$\mathbf{1 8}$ & 53.55572 & 53.81232 & 47.54399 & 86.40029 \\
$\mathbf{5 - F U}$ & 98.05718 & 77.52933 & 78.95894 & 80.42522 \\
Dox & 73.24047 & 70.01466 & 16.31232 & 21.04106
\end{tabular}

Table $2 \quad \mathrm{IC}_{50}$ of the tested compounds against HeLa cells

\begin{tabular}{ll}
\hline Compd. & $\mathrm{IC}_{50}(\mu \mathrm{M})$ \\
\hline $\mathbf{3}$ & $\mathrm{ND}$ \\
$\mathbf{4}$ & 13.2 \\
$\mathbf{5}$ & 100 \\
$\mathbf{6}$ & 77.6 \\
7 & 77.5 \\
$\mathbf{8}$ & 81.3 \\
$\mathbf{9}$ & 85.1 \\
$\mathbf{1 0}$ & $\mathrm{ND}$ \\
$\mathbf{1 1}$ & $\mathrm{ND}$ \\
$\mathbf{1 4}$ & $\mathrm{ND}$ \\
$\mathbf{1 5}$ & $\mathrm{ND}$ \\
$\mathbf{1 6}$ & $\mathrm{ND}$ \\
$\mathbf{1 6 b}$ & 11.6 \\
$\mathbf{1 6 c}$ & 0.69 \\
$\mathbf{1 6 d}$ & $\mathrm{ND}$ \\
$\mathbf{1 8}$ & 3.39 \\
$\mathbf{5 - F U}$ & $\mathrm{ND}$ \\
Dox & 2.29 \\
\hline
\end{tabular}

the comparative docking with the co-crystallized ligand compound 18 is considered a potential hit for HDAC inhibition followed by compound 16B with rooms for pharmacokinetic and target interaction optimization.

\section{Conclusion}

In conclusion, efficient and very simple methods for the synthesis of various HDAC inhibitors were executed. Some of the synthesized compounds exhibited promising antiproliferative activity against various cancer cell lines namely; HCT-116, MCF-7, PC3, A549. Compounds 16b, 16c, 18 were consistently the most active on all tested cells and showed comparable activities to the standard drugs doxorubicin and 5-
Table 3 Anticancer activity of tested compounds against HCT-116 cells

\begin{tabular}{lllll}
\multicolumn{5}{l}{ \% of cell growth treated with different (conc. $\mu \mathrm{M} \pm \mathrm{SEM}$ ) of cpds. } \\
\hline Cpds. & 0.1 & 1 & 10 & 100 \\
\hline $\mathbf{3}$ & 74.25979 & 70.00955 & 73.87775 & 69.91404 \\
$\mathbf{4}$ & 86.67622 & 75.45368 & 80.70678 & 65.52053 \\
$\mathbf{5}$ & 80.09531 & 68.47507 & 66.93548 & 54.43548 \\
$\mathbf{6}$ & 92.33871 & 93.8783 & 86.36364 & 48.86364 \\
$\mathbf{7}$ & 74.70833 & 85.58333 & 88.41667 & 86.875 \\
$\mathbf{8}$ & 71.82426 & 73.20917 & 69.532 & 64.51767 \\
$\mathbf{9}$ & 74.88061 & 74.11652 & 78.08023 & 62.89398 \\
$\mathbf{1 0}$ & 75.02388 & 72.34957 & 77.31614 & 57.06781 \\
$\mathbf{1 1}$ & 76.69532 & 71.58548 & 69.81853 & 73.68672 \\
$\mathbf{1 4}$ & 73.35244 & 69.67526 & 67.95606 & 68.33811 \\
$\mathbf{1 5}$ & 72.6361 & 69.62751 & 71.48997 & 70.63037 \\
$\mathbf{1 6 a}$ & 78.12798 & 83.52436 & 81.27985 & 79.36963 \\
$\mathbf{1 6 b}$ & 58.11843 & 61.7001 & 49.37918 & 47.94651 \\
$\mathbf{1 6 c}$ & 64.89971 & 62.89398 & 57.02006 & 55.44413 \\
$\mathbf{1 6 d}$ & 60.875 & 64.41667 & 64.79167 & 60.08333 \\
$\mathbf{1 8}$ & 63.32378 & 65.85482 & 68.62464 & 65.42502 \\
$\mathbf{5 - F U}$ & 73.35244 & 77.93696 & 69.43649 & 62.98949 \\
Dox & 82.56925 & 81.3276 & 65.234 & 82.52149
\end{tabular}

fluoro uracil. Compound $\mathbf{1 8}$ was selected as a potential lead for further optimization and development due to its interesting structural features that differs from other members of the series. The docking experiments performed substantiated the biological testing results and identified compound $\mathbf{1 8}$ as a potential HDAC inhibitor.

\section{Experimental}

\section{General}

Solvent were purified and dried by standard procedures. The boiling range of the petroleum ether used was $40-60{ }^{\circ} \mathrm{C}$. Thin

Table 4 Anticancer activity of tested compounds against MCF-7 cells $\%$ of cell growth treated with different (conc. $\mu \mathrm{M} \pm \mathrm{SEM}$ ) of cpds.

\begin{tabular}{lcccc}
\hline Cpds. & 0.1 & 1 & 10 & 100 \\
\hline $\mathbf{3}$ & 89.1342 & 78.44568 & 99.3658 & 97.3465 \\
$\mathbf{4}$ & 98.1562 & 94.49858 & 105.4714 & 93.839 \\
$\mathbf{5}$ & 105.6513 & 109.1291 & 90.90091 & 91.14076 \\
$\mathbf{6}$ & 77.58333 & 76.16667 & 72.91667 & 46.20833 \\
$\mathbf{7}$ & 88.04348 & 108.8969 & 112.4396 & 90.49919 \\
$\mathbf{8}$ & 95.57787 & 93.839 & 91.3806 & 78.48898 \\
$\mathbf{9}$ & 98.39604 & 98.69585 & 104.3322 & 82.44641 \\
$\mathbf{1 0}$ & 114.7054 & 113.806 & 116.6242 & 79.50832 \\
$\mathbf{1 1}$ & 108.4695 & 106.8505 & 102.1736 & 109.3089 \\
$\mathbf{1 4}$ & 113.4463 & 102.1736 & 104.0923 & 99.77515 \\
$\mathbf{1 5}$ & 103.9125 & 104.5121 & 98.51596 & 98.33608 \\
$\mathbf{1 6 a}$ & 111.5875 & 113.0265 & 109.5488 & 93.89897 \\
$\mathbf{1 6 b}$ & 83.2259 & 85.56438 & 77.10988 & 60.32079 \\
$\mathbf{1 6 c}$ & 78.66887 & 80.70754 & 73.09249 & 70.63409 \\
$\mathbf{1 6 d}$ & 60.875 & 64.41667 & 64.79167 & 60.08333 \\
$\mathbf{1 8}$ & 102.6533 & 105.6513 & 102.4134 & 106.9105 \\
$\mathbf{5 - F U}$ & 104.632 & 103.013 & 92.81967 & 68.53545 \\
$\mathbf{D o x}$ & 108.9492 & 115.1851 & 84.06536 & 84.42512
\end{tabular}


Table 5 Anticancer activity of tested compounds against PC3 cells

$\%$ of cell growth treated with different (conc. $\mu \mathrm{M} \pm \mathrm{SEM}$ ) of cpds.

\begin{tabular}{lllll} 
Cpds. & 0.1 & 1 & 10 & 100 \\
\hline $\mathbf{3}$ & 75.70833 & 70.70833 & 71.29167 & 67.91667 \\
$\mathbf{4}$ & 83.20833 & 69.66667 & 69 & 149.3333 \\
$\mathbf{5}$ & 78.08333 & 71.54167 & 73.58333 & 123.8333 \\
$\mathbf{6}$ & 98.39604 & 98.69585 & 104.3322 & 82.44641 \\
$\mathbf{7}$ & 85.74879 & 84.46055 & 87.39936 & 87.56039 \\
$\mathbf{8}$ & 66.75 & 65.66667 & 67.08333 & 57.70833 \\
$\mathbf{9}$ & 77.58333 & 76.16667 & 72.91667 & 46.20833 \\
$\mathbf{1 0}$ & 77.33333 & 80.83333 & 72.20833 & 47.25 \\
$\mathbf{1 1}$ & 72.41667 & 77.91667 & 71.58333 & 66.58333 \\
$\mathbf{1 4}$ & 74.70833 & 85.58333 & 88.41667 & 86.875 \\
$\mathbf{1 5}$ & 62.125 & 66.5 & 67.375 & 61.29167 \\
$\mathbf{1 6 a}$ & 89.1342 & 78.44568 & 99.3658 & 97.3465 \\
$\mathbf{1 6 b}$ & 66.20833 & 66.5 & 53.83333 & 44.08333 \\
$\mathbf{1 6 c}$ & 70.5 & 63.54167 & 55.08333 & 46.29167 \\
$\mathbf{1 6 d}$ & 81.11916 & 77.89855 & 75.60386 & 75.36232 \\
$\mathbf{1 8}$ & 59.45833 & 59.66667 & 51.20833 & 45.16667 \\
$\mathbf{5 - F U}$ & 66 & 62.25 & 49 & 50.16667 \\
Dox & 63.25 & 65.16667 & 49.875 & 49.04167
\end{tabular}

Table 6 Anticancer activity of tested compounds against A549 cells

$\%$ of cell growth treated with different (conc. $\mu \mathrm{M} \pm \mathrm{SEM}$ ) of cpds.

\begin{tabular}{llccl}
\hline Cpds. & 0.1 & 1 & 10 & 100 \\
\hline $\mathbf{3}$ & 78.55572 & 82.36804 & 70.41789 & 59.45748 \\
$\mathbf{4}$ & 80.43478 & 95.04831 & 90.05636 & 72.98712 \\
$\mathbf{5}$ & 84.29952 & 83.49436 & 85.82931 & 80.47504 \\
$\mathbf{6}$ & 88.88889 & 91.38486 & 78.7037 & 66.86795 \\
$\mathbf{7}$ & 60.875 & 64.41667 & 64.79167 & 60.08333 \\
$\mathbf{8}$ & 88.04348 & 108.8969 & 112.4396 & 90.49919 \\
$\mathbf{9}$ & 100.7246 & 94.40419 & 93.67955 & 75.60386 \\
$\mathbf{1 0}$ & 88.88889 & 91.38486 & 78.7037 & 66.86795 \\
$\mathbf{1 3}$ & 93.84058 & 87.39936 & 97.70531 & 65.29791 \\
$\mathbf{1 4}$ & 88.28502 & 87.56039 & 94.68599 & 92.3913 \\
$\mathbf{1 5}$ & 85.74879 & 84.46055 & 87.39936 & 87.56039 \\
$\mathbf{1 6 a}$ & 89.1342 & 78.44568 & 99.3658 & 97.3465 \\
$\mathbf{1 6 b}$ & 98.59098 & 86.95652 & 96.53784 & 46.61836 \\
$\mathbf{1 6 c}$ & 91.10306 & 97.26248 & 110.1449 & 46.37681 \\
$\mathbf{1 6 d}$ & 85.74879 & 84.46055 & 87.39936 & 87.56039 \\
$\mathbf{1 8}$ & 97.38325 & 93.27697 & 94.36393 & 43.19646 \\
$\mathbf{5 - F U}$ & 79.99195 & 76.24799 & 73.59098 & 66.74718 \\
Dox & 79.99195 & 62.72142 & 65.25765 & 73.79227 \\
\hline
\end{tabular}

layer chromatography (TLC): silica gel 60 F254 plastic plates (E. Merck, layer thickness $0.2 \mathrm{~mm}$ ) detected by UV absorption. Elemental analyses were performed on a Flash EA-1112 instrument at the Microanalytical laboratory, Faculty of Science, Suez Canal University, Ismailia, Egypt. Melting points were determined on a Buchi 510 melting-point apparatus and the values are uncorrected. ${ }^{1} \mathrm{H}$ and ${ }^{13} \mathrm{C}$ NMR spectra were recorded at 400 $\mathrm{MHz}$ and $100 \mathrm{MHz}$, respectively (Bruker $\mathrm{AC} 400$ ) in $\mathrm{CDCl}_{3}$ and DMSO solution with tetramethylsilane as an internal standard. The NMR analyses were performed at Faculty of Science, Sohag University. The mass spectra were measured with a KRATOS analytical compact; on MALDI-MS the spectrometer was using 2,5-dihydroxy benzoic acid (DHB) as matrix. The starting compound 3 were obtained as described in literature. ${ }^{17,18}$

3-Hydroxy-2,2-dimethyl-3-(4-nitrophenyl)-propionic acid methyl ester (3). To an anhydrous stirred solution of pyridine- $N$ oxide $(0.19 \mathrm{~g}, 0.20 \mathrm{mmol})$ and $\mathrm{LiCl}(0.17 \mathrm{~g}, 0.40 \mathrm{mmol})$ in DMF $(20 \mathrm{ml})$ were added 4-nitrobenzaldehyde $1(3.0 \mathrm{~g}, 20.0 \mathrm{mmol})$ and trimethylsilyl ketene acetal $2(5.25 \mathrm{ml}, 26.0 \mathrm{mmol})$ at room temperature under a nitrogen atmosphere. After stirring overnight, the reaction was quenched by the addition of $1 \mathrm{~N} \mathrm{HCl} \mathrm{(5}$ $\mathrm{ml}$ ), the product was extracted with ethyl acetate. The organic layer was washed with water, brine and evaporated to dryness, the product was then purified by flash column chromatography (petroleum ether-ethyl acetate) to give 3-hydroxy-2,2-dimethyl3-(4-nitrophenyl)-propionic acid methyl ester (3). $3.47 \mathrm{~g}$, yield $69 \%$ white powder. Mp $188-191{ }^{\circ} \mathrm{C} .{ }^{1} \mathrm{H}$ NMR spectrum, (400 $\mathrm{MHz}, \mathrm{CDCl}_{3}$ ), $\delta, \operatorname{ppm}(\mathrm{J}, \mathrm{Hz}): 1.15$ (s, 3H, $\left.\mathrm{CH}_{3}\right), 1.16\left(\mathrm{~s}, 3 \mathrm{H}, \mathrm{CH}_{3}\right)$, $3.42(\mathrm{~s}, 1 \mathrm{H}, \mathrm{OH}), 3.78\left(\mathrm{~s}, 3 \mathrm{H}, \mathrm{OCH}_{3}\right), 5.04(\mathrm{~s}, 1 \mathrm{H}, \mathrm{CH}), 7.51(\mathrm{~d}, J=$ $8.4 \mathrm{~Hz}, 2 \mathrm{H}, \mathrm{Ar}-\mathrm{H}), 8.20$ (d, $J=8.3 \mathrm{~Hz}, 2 \mathrm{H}, \mathrm{Ar}-\mathrm{H}) .{ }^{13} \mathrm{C}-\mathrm{NMR}(100$ $\left.\mathrm{MHz}, \mathrm{CDCl}_{3}\right)$, $\delta$, ppm: 19.23, $22.8\left(\mathrm{CH}_{3}\right), 47.7(\mathrm{C}), 52.4\left(\mathrm{OCH}_{3}\right)$, $77.8(\mathrm{CH}), 122.9,128.6,147.3,147.5$ (C-Ar), 177.7 (CO). MS (MALDI, positive mode, matrix DHB): $m / z=276(\mathrm{M}+\mathrm{Na})^{+}$. Found, \%: C, 57.12; H, 6.27; N, 5.32. For $\mathrm{C}_{12} \mathrm{H}_{15} \mathrm{NO}_{5}$ (253.3). Calculated, \%: C, 56.91; H, 5.97; N, 5.53.

3-(4-Aminophenyl)-3-hydroxy-2,2-dimethylpropionic acid methyl ester (4). $\mathrm{Pd} / \mathrm{C}$ catalyst (100 $\mathrm{mg}$ ) was added to a solution of $3(1.0 \mathrm{~g}, 4.0 \mathrm{mmol})$ dissolved in ethanol $(20 \mathrm{ml})$ and then the reaction was stirred under $\mathrm{H}_{2}$ atmosphere. After $3 \mathrm{~h}$ the hydrogen balloon was removed and the mixture was filtered through Celite, the solvent was then removed under reduce pressure and the oil formed was extracted with methylene chloride $(100 \mathrm{ml})$, washed with water and dried over sodium sulphate, filtered and evaporated in vacuum, the product was then obtained without further purification to give 3-(4aminophenyl)-3-hydroxy-2,2-dimethylpropionic acid methyl ester (4). $0.87 \mathrm{~g}$, yield 87\%, yellow powder. Mp 130-132 ${ }^{\circ} \mathrm{C} .{ }^{1} \mathrm{H}$ NMR spectrum, (400 MHz, $\left.\mathrm{CDCl}_{3}\right), \delta, \operatorname{ppm}(J, \mathrm{~Hz}): 0.90(\mathrm{~s}, 3 \mathrm{H}$, $\mathrm{CH}_{3}$ ), 1.02 (s, 3H, $\mathrm{CH}_{3}$ ), 3.58 (s, 3H, $\left.\mathrm{OCH}_{3}\right), 4.65$ (s, 1H, OH), 4.93 $\left(\mathrm{s}, 2 \mathrm{H}, \mathrm{NH}_{2}\right), 5.17(\mathrm{~s}, 1 \mathrm{H}, \mathrm{CH}), 6.50(\mathrm{~d}, J=7.9 \mathrm{~Hz}, 2 \mathrm{H}, \mathrm{Ar}-\mathrm{H}), 6.92$ (d, $J=7.9 \mathrm{~Hz}, 2 \mathrm{H}, \mathrm{Ar}-\mathrm{H}) .{ }^{13} \mathrm{C}-\mathrm{NMR}\left(100 \mathrm{MHz}, \mathrm{CDCl}_{3}\right), \delta$, ppm: 18.5, $19.4\left(\mathrm{CH}_{3}\right), 47.9(\mathrm{C}), 51.3\left(\mathrm{OCH}_{3}\right), 76.8(\mathrm{CH}), 112.8,128.0$, 128.6 (C-Ar), 176.7 (CO). MS (MALDI, positive mode, matrix DHB): $m / z=246(\mathrm{M}+\mathrm{Na})^{+}$. Found, \%: C, 64.78; H, 7.92; N, 6.09. For $\mathrm{C}_{12} \mathrm{H}_{17} \mathrm{NO}_{3}$ (223.3). Calculated, \%: C, 64.55; H, 7.67; N, 6.27.

Methyl 3-(4-(2-chloroacetamido)phenyl)-3-hydroxy-2,2dimethylpropanoate (5). To a cold solution $\left(-5{ }^{\circ} \mathrm{C}\right)$, of 4 $(2.23 \mathrm{~g}, 10.0 \mathrm{mmol})$, triethylamine $(1 \mathrm{ml})$ and DMAP $(0.122 \mathrm{~g}, 1.0$ $\mathrm{mmol})$ in methylene chloride $(60 \mathrm{ml})$, was added portion wise under stirring a cold solution $\left(0{ }^{\circ} \mathrm{C}\right)$ of chloroacetyl chloride $(1.69 \mathrm{~g}, 15.0 \mathrm{mmol})$. After stirring at the same temperature for 30 minutes, the reaction mixture was stirred at room temperature for $12 \mathrm{~h}$ The solvent was then removed under reduce pressure, the product was then obtained without further purification to give methyl 3-(4-((2-chloro-2-oxoethyl)amino)phenyl)3-hydroxy-2,2-dimethylpropanoate (5). $2.1 \mathrm{~g}$, yield 70\%, white powder. Mp 89-93 ${ }^{\circ} \mathrm{C} .{ }^{1} \mathrm{H}$ NMR spectrum, (400 $\mathrm{MHz}, \mathrm{CDCl}_{3}$ ), $\delta, \operatorname{ppm}(J, \mathrm{~Hz}): 0.90\left(\mathrm{~s}, 3 \mathrm{H}, \mathrm{CH}_{3}\right), 1.03\left(\mathrm{~s}, 3 \mathrm{H}, \mathrm{CH}_{3}\right), 3.56(\mathrm{~s}, 3 \mathrm{H}$, $\left.\mathrm{OCH}_{3}\right), 4.77\left(\mathrm{~d}, J=3.0 \mathrm{~Hz}, 2 \mathrm{H}, \mathrm{CH}_{2}\right), 5.27(\mathrm{~d}, J=3.0 \mathrm{~Hz}, 1 \mathrm{H}, \mathrm{CH})$ 
Table $7 \quad \mathrm{C}_{50}$ of the tested compounds against A549 cells

\begin{tabular}{ll}
\hline Compd. & $\mathrm{IC}_{50}(\mu \mathrm{M})$ \\
\hline $\mathbf{3}$ & $\mathrm{ND}$ \\
$\mathbf{4}$ & $\mathrm{ND}$ \\
$\mathbf{5}$ & $\mathrm{ND}$ \\
$\mathbf{6}$ & $\mathrm{ND}$ \\
$\mathbf{7}$ & $\mathrm{ND}$ \\
$\mathbf{8}$ & $\mathrm{ND}$ \\
$\mathbf{9}$ & $\mathrm{ND}$ \\
$\mathbf{1 0}$ & $\mathrm{ND}$ \\
$\mathbf{1 1}$ & $\mathrm{ND}$ \\
$\mathbf{1 4}$ & $\mathrm{ND}$ \\
$\mathbf{1 5}$ & $\mathrm{ND}$ \\
$\mathbf{1 6 A}$ & $\mathrm{ND}$ \\
$\mathbf{1 6 b}$ & 79.4 \\
$\mathbf{1 6 c}$ & 85.1 \\
$\mathbf{1 6 D}$ & $\mathrm{ND}$ \\
$\mathbf{1 8}$ & 89.2 \\
$\mathbf{5 - F U}$ & 72.4 \\
Dox & $\mathrm{ND}$ \\
&
\end{tabular}

5.55 (s, 1H, OH), 7.20-7.37 (m, 4H, Ar-H), 8.70 (bs, $1 \mathrm{H}, \mathrm{NH}) .{ }^{13} \mathrm{C}-$ NMR (100.0 MHz, $\left.\mathrm{CDCl}_{3}\right), \delta$, ppm: 20.0, $22.5\left(\mathrm{CH}_{3}\right), 42.4(\mathrm{C}), 46.1$ $\left(\mathrm{CH}_{2}\right), 55.3\left(\mathrm{OCH}_{3}\right), 75.3(\mathrm{CH}), 127.3,128.5,130.1,136.6,138.9$ (C-Ar), 171.0, 173.3 (2 CO). MS (MALDI, positive mode, matrix DHB): $m / z=322.0(\mathrm{M}+\mathrm{Na})^{+}$. Found, \%: C, 55.79; H, 6.33; N, 4.89. For $\mathrm{C}_{14} \mathrm{H}_{18} \mathrm{ClNO}_{4}$ (299.8). Calculated, \%: C, 56.10; H, 6.05; N, 4.67.

Methyl 3-hydroxy-2,2-dimethyl-3-(4-(2-(phenylamino) acetamido)phenyl)propanoate (6). A mixture of methyl 3-(4((2-chloro-2-oxoethyl)amino)phenyl)-3-hydroxy-2,2-dimethyl propanoate (5) $(2.99 \mathrm{~g}, 10.0 \mathrm{mmol})$ and aniline (1.40 g, 15.0 mmol) was refluxed in pyridine $(30 \mathrm{ml})$ for 10 hours. After cooling to room temperature, the solvent was then removed under reduce pressure and the oil formed was extracted with methylene chloride $(100 \mathrm{ml})$, washed with water and dried over sodium sulphate, filtered and evaporated in vacuum, the product was then obtained without further purification to give methyl 3-hydroxy-2,2-dimethyl-3-(4-(2-(phenylamino)acetamido) phenyl)propanoate (6). 3.0 g, yield $84 \%$, white powder. Mp 172$176{ }^{\circ} \mathrm{C} .{ }^{1} \mathrm{H}$ NMR spectrum, (400 MHz, $\left.\mathrm{CDCl}_{3}\right), \delta$, ppm (J, Hz): 1.05 $\left(\mathrm{s}, 3 \mathrm{H}, \mathrm{CH}_{3}\right), 1.08\left(\mathrm{~s}, 3 \mathrm{H}, \mathrm{CH}_{3}\right), 3.52\left(\mathrm{~s}, 3 \mathrm{H}, \mathrm{OCH}_{3}\right), 4.24(\mathrm{~d}, J=$ $3.0 \mathrm{~Hz}, 2 \mathrm{H}, \mathrm{CH}_{2}$ ), 5.14 (s, 1H, CH), 5.69 (bs, 1H, OH), 6.08 (bs, $1 \mathrm{H}$, $\mathrm{NH}), 7.44-8.08$ (m, 10H, NH, Ar-H). ${ }^{13} \mathrm{C}-\mathrm{NMR}\left(100 \mathrm{MHz}, \mathrm{CDCl}_{3}\right.$ ), $\delta$, ppm: $20.2\left(\mathrm{CH}_{3}\right), 22.4\left(\mathrm{CH}_{3}\right), 47.1(\mathrm{C}), 50.4\left(\mathrm{CH}_{2}\right), 53.4\left(\mathrm{OCH}_{3}\right)$, $75.5(\mathrm{CH}), 127.1,128.7,129.0,129.4,130.2$, 133.9, 136.6, 139.8, 140.9, 153.3 (C-Ar), 168.6, 173.8 (2 CO). MS (MALDI, positive mode, matrix DHB): $m / z=379.0(\mathrm{M}+\mathrm{Na})^{+}$. Found, \%: C, 67.36; $\mathrm{H}, 6.52 ; \mathrm{N}, 7.91$. For $\mathrm{C}_{20} \mathrm{H}_{24} \mathrm{~N}_{2} \mathrm{O}_{4}$ (356.4). Calculated, \%: C, 67.40; H, 6.79; N, 7.86.

Methyl 2,2-dimethyl-3-(4-(2-(phenylamino)acetamido) phenyl)-3-(1H-1,2,4-triazol-1-yl)propanoate (7). To a solution of $6(0.53 \mathrm{~g}, 1.5 \mathrm{mmol})$ in anhydrous acetonitrile $(20 \mathrm{ml})$ was added triazole $(6.0 \mathrm{mmol})$ and CDI $(3.0 \mathrm{mmol})$. The mixture was then heated under reflux for $48 \mathrm{~h}$. The reaction mixture was allowed to cool and then extracted with ethyl acetate. The organic layer was washed by water and dried over sodium sulphate, filtered and evaporated under reduce vacuum. The product was purified by flash column chromatography to give methyl 2,2-dimethyl-3(4-(2-(phenylamino)acetamido)phenyl)-3-(1H-1,2,4-triazol-1-yl) propanoate (7). $0.4 \mathrm{~g}$, yield $67 \%$, yellow powder. Mp 183$185{ }^{\circ} \mathrm{C} .{ }^{1} \mathrm{H}$ NMR spectrum, $\left(400 \mathrm{MHz}, \mathrm{CDCl}_{3}\right), \delta, \mathrm{ppm}(J, \mathrm{~Hz})$ : $1.01\left(\mathrm{~s}, 3 \mathrm{H}, \mathrm{CH}_{3}\right), 1.09$ (s, 3H, $\left.\mathrm{CH}_{3}\right), 3.29$ (s, 3H, $\left.\mathrm{OCH}_{3}\right), 4.01$ (d, $\left.J=3.0 \mathrm{~Hz}, 2 \mathrm{H}, \mathrm{CH}_{2}\right), 4.86(\mathrm{~s}, 1 \mathrm{H}, \mathrm{CH}), 6.36$ (bs, $\left.1 \mathrm{H}, \mathrm{NH}\right), 7.21-$ $7.38(\mathrm{~m}, 9 \mathrm{H}, \mathrm{Ar}-\mathrm{H}), 8.45(\mathrm{~s}, 1 \mathrm{H}, \mathrm{Ar}-\mathrm{H}), 8.57$ (s, 1H, Ar-H), 9.86 (bs, 1H, NH). ${ }^{13} \mathrm{C}-\mathrm{NMR}\left(100 \mathrm{MHz}, \mathrm{CDCl}_{3}\right.$ ), $\delta$, ppm: 20.0, 22.3 $\left(\mathrm{CH}_{3}\right), 45.8(\mathrm{C}), 52.3\left(\mathrm{CH}_{2}\right), 53.4\left(\mathrm{OCH}_{3}\right), 69.7(\mathrm{CH}), 127.0$, 127.2, 128.8, 130.6, 132.1, 133.9, 145.1 (C-Ar), 166.5, 170.3 (2 CO). MS (MALDI, positive mode, matrix DHB): $m / z=430.0$ (M $+\mathrm{Na})^{+}$. Found, \%: C, 65.05; H, 5.88; N, 17.02. For $\mathrm{C}_{22} \mathrm{H}_{25} \mathrm{~N}_{5} \mathrm{O}_{3}$ (407.5). Calculated, \%: C, 64.85; H, 6.18; N, 17.19.

$\mathrm{N}$-Hydroxy-2,2-dimethyl-3-(4-(2-(phenylamino)acetamido) phenyl)-3-(1H-1,2,4-triazol-1-yl)propanamide (8). To a solution of $7(0.41 \mathrm{~g}, 1.0 \mathrm{mmol})$ was added to hydroxyl amine hydrochloride $(3.0 \mathrm{mmol})$ and $\mathrm{KOH}(6.0 \mathrm{mmol})$. The reaction mixture was refluxed for $4 \mathrm{~h}$, after cooling to temperature the

Table 8 Summarized ligand-receptor interactions of the docked compounds compared to the original ligand

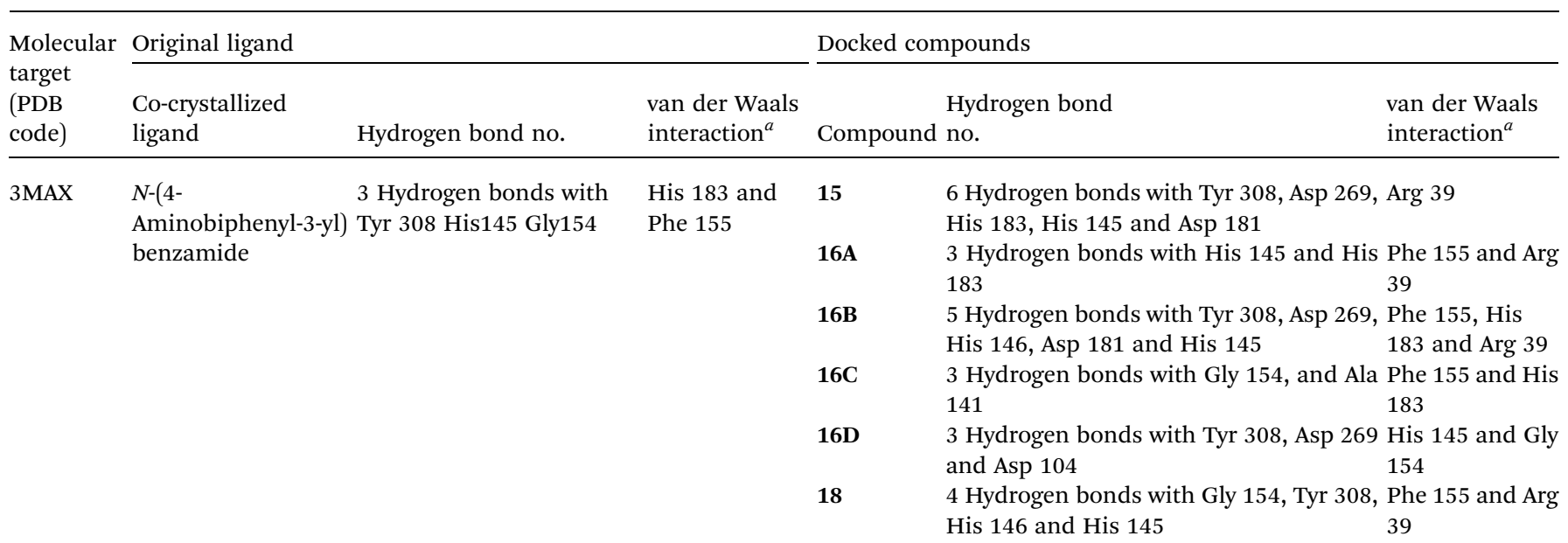

${ }^{a}$ van der Waals interactions are arene-arene interactions or arene-cation interaction. 


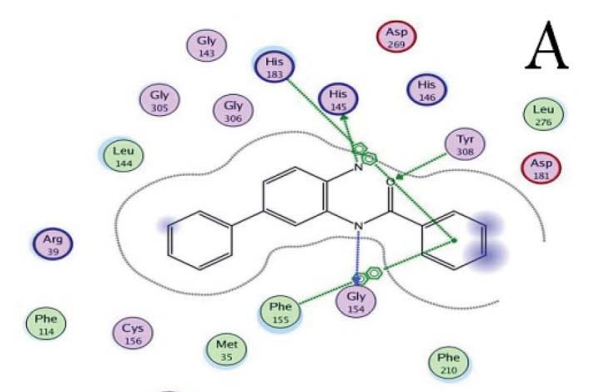

(10.)
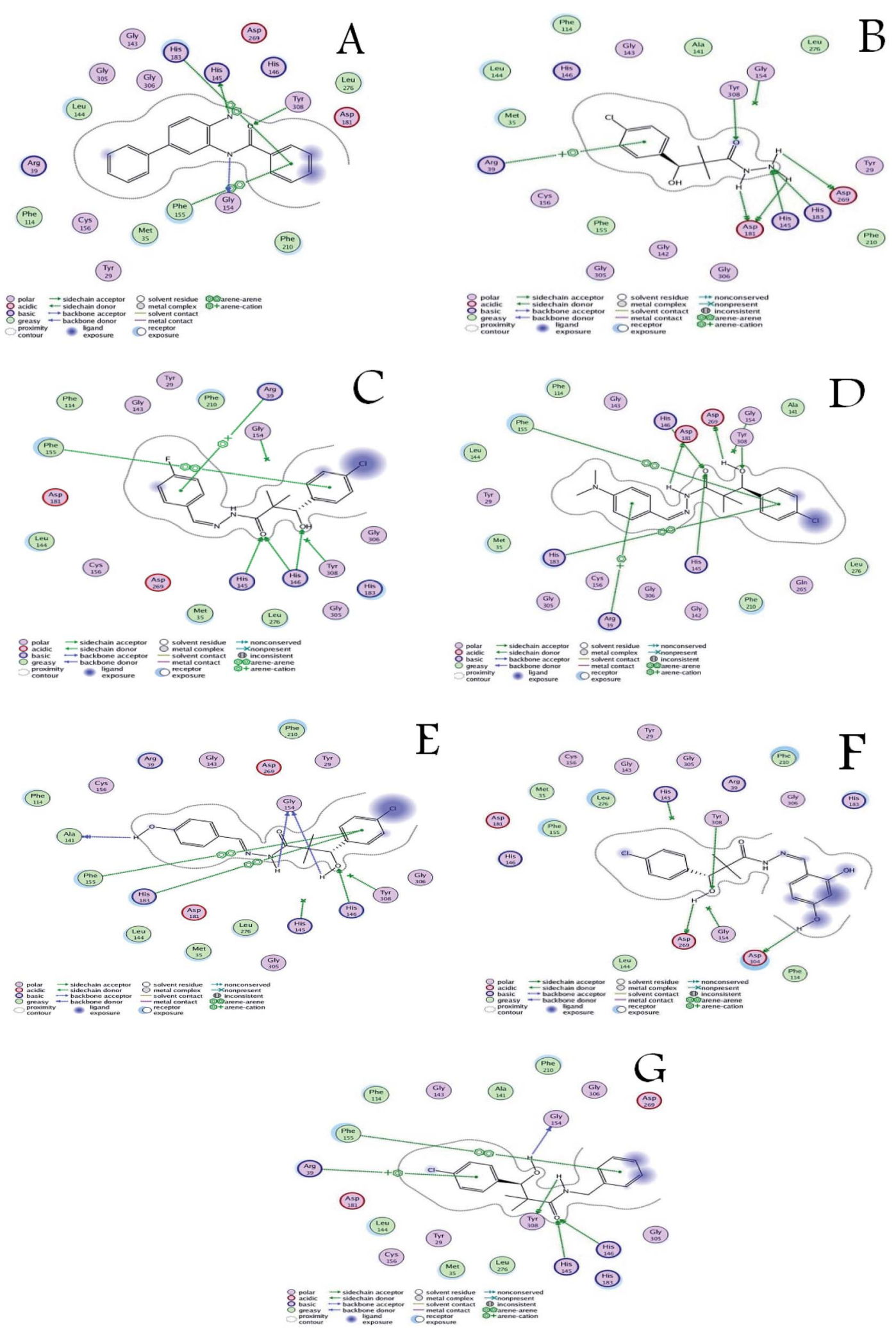

Fig. 3 (A) Ligand-receptor interactions of the original ligand, and (B-G) ligand-receptor interactions of the docked compounds 15, 16a-d and 18 respectively.

precipitated was filtered off, washed with ethanol followed by yl)propanamide (8). 0.23 g, yield 58\%, white crystals. Mp 231recrystallization from ethanol to give $N$-hydroxy-2,2-dimethyl- $236{ }^{\circ} \mathrm{C} .{ }^{1} \mathrm{H}$ NMR spectrum, $\left(400 \mathrm{MHz}, \mathrm{DMSO}-\mathrm{d}_{6}\right), \delta$, ppm $(J$, 3-(4-(2-(phenylamino)acetamido)phenyl)-3-(1H-1,2,4-triazol-1-

$\mathrm{Hz}): 1.04\left(\mathrm{~s}, 3 \mathrm{H}, \mathrm{CH}_{3}\right), 1.11\left(\mathrm{~s}, 3 \mathrm{H}, \mathrm{CH}_{3}\right), 3.92\left(\mathrm{~s}, 2 \mathrm{H}, \mathrm{CH}_{2}\right), 5.24$ 
(s, 1H, CH), 6.74 (bs, 1H, NH), 6.94-7.49 (m, 10H, NH, Ar-H), 8.33 (s, 1H, Ar-H), 8.85 (s, 1H, Ar-H), 11.0 (bs, 1H, NH), 11.4 (bs, 1H, OH). ${ }^{13} \mathrm{C}-\mathrm{NMR}\left(100 \mathrm{MHz}, \mathrm{CDCl}_{3}\right), \delta$, ppm: 21.2, 22.5 $\left(\mathrm{CH}_{3}\right), 47.1(\mathrm{C}), 52.1\left(\mathrm{CH}_{2}\right), 68.9(\mathrm{CH}), 127.3,127.7,129.0$, 130.2, 131.6, 132.1, 133.9, 136.2, 145.1 (C-Ar), 167.5, 172.3 (2 CO). MS (MALDI, positive mode, matrix DHB): $m / z=431.0$ (M $+\mathrm{Na})^{+}$. Found, \%: C, 61.92; H, 5.64; N, 20.09. For $\mathrm{C}_{21} \mathrm{H}_{24} \mathrm{~N}_{6} \mathrm{O}_{3}$ (408.5). Calculated, \%: C, 61.75; H, 5.92; N, 20.58.

Methyl 3-hydroxy-3-(4-(2-((2-methoxy-2-oxoethyl)amino) acetamido)phenyl)-2,2-dimethyl propanoate (9). A mixture of 3-[4-(2-chloro-acetylamino)-phenyl]-3-hydroxy-2,2-dimethylpropionic acid methyl ester (5) (2.99 g, $10.0 \mathrm{mmol})$ and glycine methyl ester hydrochloride $(2.50 \mathrm{~g}, 20.0 \mathrm{mmol})$ was refluxed in pyridine $(30 \mathrm{ml})$ for 10 hours. After cooling to room temperature, the solvent was then removed under reduce pressure and the oil formed was extracted with methylene chloride $(100 \mathrm{ml})$, washed with water and dried over sodium sulphate, filtered and evaporated in vacuum, the product was crystallized from ethyl acetate-petroleum ether to give methyl 3-hydroxy-3-(4-(2-((2-methoxy-2oxoethyl)amino)acetamido)phenyl)-2,2-

dimethylpropanoate (9). $2.5 \mathrm{~g}$, yield 71\%, white powder. Mp 79-81 ${ }^{\circ} \mathrm{C} .{ }^{1} \mathrm{H}$ NMR spectrum, (400 $\left.\mathrm{MHz}, \mathrm{CDCl}_{3}\right), \delta, \mathrm{ppm}(J$, $\mathrm{Hz}): 1.07\left(\mathrm{~s}, 3 \mathrm{H}, \mathrm{CH}_{3}\right), 1.13\left(\mathrm{~s}, 3 \mathrm{H}, \mathrm{CH}_{3}\right), 3.57-3.79(\mathrm{~m}, 2 \mathrm{H}$, $\left.\mathrm{CH}_{2}\right), 3.83,3.86\left(2 \mathrm{~s}, 6 \mathrm{H}, \mathrm{OCH}_{3}\right), 4.21\left(\mathrm{~d}, J=6.0 \mathrm{~Hz}, 2 \mathrm{H}, \mathrm{CH}_{2}\right)$, $5.01(\mathrm{~d}, J=3.0 \mathrm{~Hz}, 1 \mathrm{H}, \mathrm{CH}), 5.64$ (bs, $1 \mathrm{H}, \mathrm{OH}), 6.38$ (bs, $1 \mathrm{H}$, $\mathrm{NH}), 7.44-7.69(\mathrm{~m}, 5 \mathrm{H}, \mathrm{NH}, \mathrm{Ar}-\mathrm{H}) .{ }^{13} \mathrm{C}-\mathrm{NMR}(100 \mathrm{MHz}$, $\left.\mathrm{CDCl}_{3}\right), \delta$, ppm: 20.5, $22.06\left(\mathrm{CH}_{3}\right), 44.4(\mathrm{C}), 47.0\left(\mathrm{CH}_{2}\right), 49.0$ $\left(\mathrm{CH}_{2}\right), 58.6,59.0\left(2 \mathrm{OCH}_{3}\right), 75.8(\mathrm{CH}), 127.1,128.7,129.0$, 129.4, 130.4, 133.9, 136.6 (C-Ar), 160.6, 173.3 (2 CO). MS (MALDI, positive mode, matrix DHB): $m / z=375.0(\mathrm{M}+\mathrm{Na})^{+}$. Found, \%: C, 58.11; H, 7.21; N, 8.03. For $\mathrm{C}_{17} \mathrm{H}_{24} \mathrm{~N}_{2} \mathrm{O}_{6}(352.4)$. Calculated, \%: C, 57.94; H, 6.87; N, 7.95.

Methyl 3-(4-(2-((2-methoxy-2-oxoethyl)amino)acetamido) phenyl)-2,2-dimethyl-3-(1H-1,2,4-triazol-1-yl)propanoate (10). Prepared via reaction of 9 with CDI and triazole, after $48 \mathrm{~h}$ reflux, column chromatography (ethyl acetate-petroleum ether) gave this product 10, yield $71 \%$, yellowish oil. ${ }^{1} \mathrm{H}$ NMR spectrum, (400 MHz, $\mathrm{CDCl}_{3}$ ), $\delta, \operatorname{ppm}(\mathrm{J}, \mathrm{Hz}): 1.04\left(\mathrm{~s}, 3 \mathrm{H}, \mathrm{CH}_{3}\right), 1.19$ (s, 3H, $\left.\mathrm{CH}_{3}\right), 3.53-3.80\left(\mathrm{~m}, 2 \mathrm{H}, \mathrm{CH}_{2}\right), 3.83,3.86\left(2 \mathrm{~s}, 6 \mathrm{H}, \mathrm{OCH}_{3}\right)$, $4.25\left(\mathrm{~d}, J=6.0 \mathrm{~Hz}, 2 \mathrm{H}, \mathrm{CH}_{2}\right), 5.37(\mathrm{~s}, 1 \mathrm{H}, \mathrm{CH}), 7.19(\mathrm{bs}, 1 \mathrm{H}, \mathrm{NH})$, 7.47-8.45 (m, 7H, NH, Ar-H). ${ }^{13} \mathrm{C}-\mathrm{NMR}$ (100 MHz, $\mathrm{CDCl}_{3}$ ),

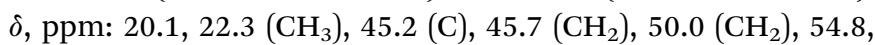
$56.9\left(2 \mathrm{OCH}_{3}\right), 73.3(\mathrm{CH}), 128.5,129.0,129.3,137.2,139.5,141.4$, 153.5, 154.9 (C-Ar), 170.5, 172.8 (2 CO). MS (MALDI, positive mode, matrix DHB): $m / z=426(\mathrm{M}+\mathrm{Na})^{+}$. Found, \%: $\mathrm{C}, 56.34 ; \mathrm{H}$, 6.67; N, 17.71. For $\mathrm{C}_{19} \mathrm{H}_{25} \mathrm{~N}_{5} \mathrm{O}_{5}$ (403.4). Calculated, \%: C, 56.57; $\mathrm{H}, 6.25 ; \mathrm{N}, 17.36$.

$\mathrm{N}$-Hydroxy-3-(4-(2-((2-(hydroxyamino)-2-oxoethyl)amino) acetamido)phenyl)-2,2-dimethyl-3-(1H-1,2,4-triazol-1-yl) propanamide (11). Prepared via reaction of 10 with hydroxyl amine hydrochloride in alcoholic $\mathrm{KOH}$, after $4 \mathrm{~h}$, stirred, filtration and washed by ethanol gave this product 11. Yield $74 \%$, white crystals. Mp $154-157{ }^{\circ} \mathrm{C} .{ }^{1} \mathrm{H}$ NMR spectrum, (400 MHz, DMSO-d ${ }_{6}$ ), $\delta, \operatorname{ppm}(J, \mathrm{~Hz}): 1.05\left(\mathrm{~s}, 3 \mathrm{H}, \mathrm{CH}_{3}\right), 1.09$ (s, $\left.3 \mathrm{H}, \mathrm{CH}_{3}\right), 3.51-3.67\left(\mathrm{~m}, 2 \mathrm{H}, \mathrm{CH}_{2}\right), 3.98(\mathrm{~d}, J=3.0 \mathrm{~Hz}, 2 \mathrm{H}$, $\left.\mathrm{CH}_{2}\right), 5.30(\mathrm{~s}, 1 \mathrm{H}, \mathrm{CH}), 6.10(\mathrm{bs}, 1 \mathrm{H}, \mathrm{NH}), 7.19-8.05(\mathrm{~m}, 8 \mathrm{H}, 2$
$\mathrm{NH}, \mathrm{Ar}-\mathrm{H}$ ), 9.00 (bs, 1H, NH), 10.15 (bs, 2H, $2 \mathrm{OH}) .{ }^{13} \mathrm{C}-\mathrm{NMR}$ (100 MHz, DMSO-d ${ }_{6}$ ), $\delta$, ppm: 20.0, $21.1\left(\mathrm{CH}_{3}\right), 42.4$ (C), 49.4 $\left(\mathrm{CH}_{2}\right), 52.0\left(\mathrm{CH}_{2}\right), 74.7(\mathrm{CH}), 128.5,129.0,129.3,129.9$, 137.2, 139.5, 141.4, 153.6 (C-Ar), 173.8, 174.9 (2 CO). MS (MALDI, positive mode, matrix DHB): $m / z=428.0(\mathrm{M}+\mathrm{Na})^{+}$. Found, \%: C, 50.21; $\mathrm{H}, 5.52 ; \mathrm{N}, 24.07$. For $\mathrm{C}_{17} \mathrm{H}_{23} \mathrm{~N}_{7} \mathrm{O}_{5}$ (405.4). Calculated, \%: C, 50.36; H, 5.72; N, 24.18.

Preparation of methyl 3-(4-chlorophenyl)-3-hydroxy-2,2dimethylpropanoate (14). To a solution of 4-chlorobenzaldehyde (12) $(0.7 \mathrm{~g}, 5.0 \mathrm{mmol})$ and $\mathrm{Zn}(6.0 \mathrm{mmol})$, in benzene was added methyl 2-bromo-2-methylpropanoate (13) $(1.0 \mathrm{ml}, 5.0 \mathrm{mmol})$. The reaction mixture was refluxed for $15 \mathrm{~h}$. The reaction mixture was cooled, evaporated under reduced pressure and was then purified by flash column chromatography (petroleum ether-ethyl acetate). $0.96 \mathrm{~g}$, yield 79\%, white crystals. Mp 62-63 ${ }^{\circ} \mathrm{C} .{ }^{1} \mathrm{H}$ NMR spectrum, (400 MHz, $\mathrm{CDCl}_{3}$ ), $\delta, \operatorname{ppm}(J, \mathrm{~Hz}): 1.11\left(\mathrm{~s}, 3 \mathrm{H}, \mathrm{CH}_{3}\right), 1.14\left(\mathrm{~s}, 3 \mathrm{H}, \mathrm{CH}_{3}\right), 3.20(\mathrm{bs}, 1 \mathrm{H}$, $\mathrm{OH}), 3.73\left(\mathrm{~s}, 3 \mathrm{H}, \mathrm{OCH}_{3}\right), 4.88(\mathrm{~s}, 1 \mathrm{H}, \mathrm{CH}), 7.24$ (d, $J=8.4,2 \mathrm{H}, \mathrm{Ar}-$ $\mathrm{H}), 7.29(\mathrm{~d}, J=8.4,2 \mathrm{H}, \mathrm{Ar}-\mathrm{H}) ;{ }^{13} \mathrm{C}-\mathrm{NMR}\left(100 \mathrm{MHz}, \mathrm{CDCl}_{3}\right.$ ), $\delta$, ppm: 18.9, $22.7\left(\mathrm{CH}_{3}\right), 47.5(\mathrm{C}), 52.1\left(\mathrm{OCH}_{3}\right), 77.8(\mathrm{CH}), 127.8$, 128.9, 133.4, 138.3 (C-Ar), 177.9 (CO). MS (MALDI, positive mode, matrix DHB): $m / z=265.0(\mathrm{M}+\mathrm{Na})^{+}$. Found, \%: C, 58.92; $\mathrm{H}, 6.07$. For $\mathrm{C}_{12} \mathrm{H}_{15} \mathrm{ClO}_{3}$ (242.7). Calculated, \%: C, 59.39; H, 6.23.

3-(4-Chlorophenyl)-3-hydroxy-2,2-dimethylpropanehydrazide (15). To a solution of methyl 3-(4-chlorophenyl)-3-hydroxy-2,2dimethylpropanoate (14) (1.93 g, $8.0 \mathrm{mmol})$ in methanol (50 $\mathrm{ml})$, hydrazine hydrate $(3 \mathrm{ml}, 48.0 \mathrm{mmol})$ was added. The reaction mixture was refluxed for $8 \mathrm{~h}$, after cooling to temperature the precipitated hydrazide was filtered off, washed with water and ethanol followed by recrystallization from aqueous ethanol to give 3-(4-chlorophenyl)-3-hydroxy-2,2-dimethylpropanehydrazide (15). $1.7 \mathrm{~g}$, yield 88\%, white crystals. Mp 96-98 ${ }^{\circ} \mathrm{C} .{ }^{1} \mathrm{H}$ NMR spectrum, (400 MHz, $\mathrm{CDCl}_{3}$ ), $\delta, \operatorname{ppm}(J, \mathrm{~Hz}): 0.90\left(\mathrm{~s}, 3 \mathrm{H}, \mathrm{CH}_{3}\right)$, $1.03\left(\mathrm{~s}, 3 \mathrm{H}, \mathrm{CH}_{3}\right), 4.17$ (bs, 2H, $\left.\mathrm{NH}_{2}\right), 4.77$ (s, 1H, CH), 5.55 (d, J= $3.0 \mathrm{~Hz}, 1 \mathrm{H}, \mathrm{OH}), 7.25-7.34(\mathrm{~m}, 5 \mathrm{H}, \mathrm{Ar}-\mathrm{H}+\mathrm{NH}) .{ }^{13} \mathrm{C}-\mathrm{NMR}(100$ $\left.\mathrm{MHz}, \mathrm{CDCl}_{3}\right)$, $\delta$, ppm: 19.2, $23.0\left(\mathrm{CH}_{3}\right), 49.1(\mathrm{C}), 78.2(\mathrm{CH}), 127.7$, 129.1, 132.6, 136.5, 139.4 (C-Ar), 179.3 (CO). MS (MALDI, positive mode, matrix DHB): $m / z=265.0(\mathrm{M}+\mathrm{Na})^{+}$. Found, \%: C, 54.23; $\mathrm{H}, 6.18$; $\mathrm{N}, 11.81$. For $\mathrm{C}_{11} \mathrm{H}_{15} \mathrm{ClN}_{2} \mathrm{O}_{2}$ (242.7). Calculated, \%: C, 54.44; H, 6.23; N, 11.54 .

General procedure for synthesis of 3-(4-chlorophenyl)- $\mathrm{N}$-arylid ene-2,2-dimethylpropane hydrazide 16a-d.

A mixture of 3-(4-chlorophenyl)-3-hydroxy-2,2-dimethylpropane hydrazide (15) $(2.1 \mathrm{~g}, 0.90 \mathrm{mmol})$ and aldehydes $(1.0 \mathrm{mmol})$ were refluxed in ethanol $(30 \mathrm{ml})$ for 6 hours. After cooling to room temperature, the resulting solid was filtered, washed with ethanol and recrystallized from ethanol.

3-(4-Chlorophenyl)- $N$-(4-fluorobenzylidene)-3-hydroxy-2,2dimethyl propanehydrazide (16a). $2.2 \mathrm{~g}$, ield 73\%, yellow crystals. Mp $159-161{ }^{\circ} \mathrm{C}$. ${ }^{1} \mathrm{H}$ NMR spectrum, $(400 \mathrm{MHz}$, DMSO-d $\left.{ }_{6}\right), \delta, \operatorname{ppm}(J, \mathrm{~Hz}): 1.03\left(\mathrm{~s}, 3 \mathrm{H}, \mathrm{CH}_{3}\right), 1.09\left(\mathrm{~s}, 3 \mathrm{H}, \mathrm{CH}_{3}\right)$, $4.88(\mathrm{~d}, J=3.0 \mathrm{~Hz}, 1 \mathrm{H}, \mathrm{CH}), 5.75$ (d, $J=3.0 \mathrm{~Hz}, 1 \mathrm{H}, \mathrm{OH}), 7.33-$ 7.37 (m, 8H, Ar-H), 8.43 (s, 1H, CH), 10.80 (bs, $1 \mathrm{H}, \mathrm{NH}) .{ }^{13} \mathrm{C}-$ NMR (100 MHz, DMSO-d $\left.{ }_{6}\right), \delta$, ppm: 20.7, $22.5\left(\mathrm{CH}_{3}\right), 47.3(\mathrm{C})$, $76.5(\mathrm{CH}), 116.4,116.6,127.8,129.5,129.8,131.0,131.1$, 
141.6, 146.2, 160.7, 163.2, 165.6 (CH, C-Ar), 172.6 (CO). MS (MALDI, positive mode, matrix DHB): $m / z=371.0(\mathrm{M}+\mathrm{Na})^{+}$. Found, \%: C, 62.07; H, 5.53; N, 8.11. For $\mathrm{C}_{18} \mathrm{H}_{18} \mathrm{ClFN}_{2} \mathrm{O}_{2}$ (348.8). Calculated, \%: C, 61.98; H, 5.20; N, 8.03.

3-(4-Chlorophenyl)- $N$-(4-(dimethylamino)benzylidene)-3hydroxy-2,2-dimethylpropane hydrazide (16b). $2.5 \mathrm{~g}$, yield $80 \%$, white crystals. Mp $220-222{ }^{\circ} \mathrm{C}$. ${ }^{1} \mathrm{H}$ NMR spectrum, (400 MHz, DMSO-d $\left.\mathrm{d}_{6}\right), \delta, \operatorname{ppm}(J, \mathrm{~Hz}): 1.02\left(\mathrm{~s}, 3 \mathrm{H}, \mathrm{CH}_{3}\right), 1.08(\mathrm{~s}, 3 \mathrm{H}$, $\left.\mathrm{CH}_{3}\right), 3.28\left(\mathrm{~s}, 6 \mathrm{H}, 2 \mathrm{CH}_{3}\right), 4.86(\mathrm{~d}, J=3.0 \mathrm{~Hz}, 1 \mathrm{H}, \mathrm{CH}), 5.72(\mathrm{~d}$, $J=3.0 \mathrm{~Hz}, 1 \mathrm{H}, \mathrm{OH}), 6.75-6.78(\mathrm{~m}, 2 \mathrm{H}, \mathrm{Ar}-\mathrm{H}), 7.30-7.67(\mathrm{~m}$, $6 \mathrm{H}, \mathrm{Ar}-\mathrm{H}), 8.50$ (s, 1H, CH), 10.46 (bs, 1H, NH). ${ }^{13} \mathrm{C}-\mathrm{NMR}$ (100 MHz, DMSO-d 6 ), $\delta$, ppm: 20.8, $22.5\left(\mathrm{CH}_{3}\right), 40.2$ (2 $\left.\mathrm{CH}_{3}\right), 47.2(\mathrm{C}), 76.5(\mathrm{CH}), 112.2,112.3,122.1,127.8,128.7$, 129.8, 129.9, 132.0, 141.8, 148.3, 151.9, 152.5, 160.2 (CH, C$\mathrm{Ar}$ ), 172.1 (CO). MS (MALDI, positive mode, matrix DHB): $\mathrm{m} / \mathrm{z}$ $=396.0(\mathrm{M}+\mathrm{Na})^{+}$. Found, \%: C, 64.43; H, 6.66; N, 11.59. For $\mathrm{C}_{20} \mathrm{H}_{24} \mathrm{ClN}_{3} \mathrm{O}_{2}$ (373.9). Calculated, \%: C, 64.25; H, 6.47; N, 11.24 .

3-(4-Chlorophenyl)-3-hydroxy- $\mathrm{N}$-(2-hydroxybenzylidene)-2,2dimethylpropanehydrazide (16c). $2.5 \mathrm{~g}$, yield $83 \%$, white crystals. Mp 165-167 ${ }^{\circ} \mathrm{C} .{ }^{1} \mathrm{H}$ NMR spectrum, (400 MHz, DMSO-d 6 ), $\delta$, ppm (J, Hz): 1.04 (s, 3H, $\left.\mathrm{CH}_{3}\right), 1.11\left(\mathrm{~s}, 3 \mathrm{H}, \mathrm{CH}_{3}\right), 4.89(\mathrm{~s}, 1 \mathrm{H}$, $\mathrm{CH}$ ), 5.75 (bs, 1H, OH), 6.92 (d, J=6.0 Hz, 2H, Ar-H), 7.29-7.47 (m, 6H, Ar-H), 8.59 (s, 1H, CH), 11.08 (bs, 1H, NH), 11.40 (bs, $1 \mathrm{H}, \mathrm{OH}) .{ }^{13} \mathrm{C}-\mathrm{NMR}$ (100 MHz, DMSO-d 6 ), $\delta, \mathrm{ppm:} \mathrm{19.9,} 20.6$ $\left(\mathrm{CH}_{3}\right), 40.1$ (C), $81.7(\mathrm{CH}), 107.8,111.1,111.6,114.8,115.6$, 121.1, 122.3, 125.3, 128.0, 132.0, 142.5, 144.1, 154.4 (CH, C-Ar), 190.3 (CO). MS (MALDI, positive mode, matrix DHB): $m / z=$ $369.0(\mathrm{M}+\mathrm{Na})^{+}$. Found, \%: C, 62.63; H, 5.42; N, 8.31. For $\mathrm{C}_{18} \mathrm{H}_{19} \mathrm{ClN}_{2} \mathrm{O}_{3}$ (346.8). Calculated, \%: C, 62.34; H, 5.52; N, 8.08.

3-(4-Chlorophenyl)- $\mathrm{N}$-(2,4-dihydroxybenzylidene)-3-hydroxy2,2-dimethylpropanehydrazide (16d). $2.3 \mathrm{~g}$, yield 70\%, white crystals. Mp 241-243 ${ }^{\circ} \mathrm{C} .{ }^{1} \mathrm{H}$ NMR spectrum, (400 MHz, DMSO$\left.\mathrm{d}_{6}\right), \delta, \operatorname{ppm}(J, \mathrm{~Hz}): 1.01\left(\mathrm{~s}, 3 \mathrm{H}, \mathrm{CH}_{3}\right), 1.09\left(\mathrm{~s}, 3 \mathrm{H}, \mathrm{CH}_{3}\right), 4.86(\mathrm{~d}, J$ $=3.0 \mathrm{~Hz}, 1 \mathrm{H}, \mathrm{CH}), 5.75(\mathrm{~d}, J=3.0 \mathrm{~Hz}, 1 \mathrm{H}, \mathrm{OH}), 6.30-6.37(\mathrm{~m}$, 2H, Ar-H), 7.21-7.38 (m, 5H, Ar-H), 8.45 (s, 1H, CH), 9.86 (bs, 1H, NH), 10.86 (bs, 1H, OH), 11.57 (bs, 1H, OH). ${ }^{13} \mathrm{C}-\mathrm{NMR}(100$ MHz, DMSO-d $\left.{ }_{6}\right), \delta$, ppm: 20.49, $22.4\left(\mathrm{CH}_{3}\right), 47.2(\mathrm{C}), 76.5(\mathrm{CH})$, 103.2 , 108.0, 111.0, 127.8, 129.8, 131.9, 132.0, 133.4, 141.6, 149.3, 160.0, 161.0 (CH, C-Ar), 172.1 (CO). MS (MALDI, positive mode, matrix DHB): $m / z=385.0(\mathrm{M}+\mathrm{Na})^{+}$. Found, \%: C, 59.73; $\mathrm{H}, 5.43$; N, 7.48. For $\mathrm{C}_{18} \mathrm{H}_{19} \mathrm{ClN}_{2} \mathrm{O}_{4}$ (362.8). Calculated, \%: C, 59.59; H, 5.28; N, 7.72.

$\mathrm{N}$-Benzyl-3-(4-chlorophenyl)-3-hydroxy-2,2-dimethylpropanamide (18). To a cold solution $\left(-5^{\circ} \mathrm{C}\right)$, of hydrazide $15(2.0 \mathrm{~g}, 8.0 \mathrm{mmol})$ in acetic acid $(60 \mathrm{ml})$, hydrochloric acid $(5 \mathrm{~N}, 30 \mathrm{ml})$, was added portion wise under stirring a cold solution $\left(0{ }^{\circ} \mathrm{C}\right)$ of sodium nitrite $(0.7 \mathrm{~g}$, $10.0 \mathrm{mmol})$ in water $(30 \mathrm{ml})$. After stirring at the same temperature for 30 minutes, the in situ generated azide 17 was extracted with cold ethyl acetate and washed successively with cold water, $5 \% \mathrm{NaHCO}_{3}$ and water. After drying over anhydrous sodium sulphate, the azide 17 was used without further purification in the next step. Benzyl amine ( $0.90 \mathrm{~g}, 9.0 \mathrm{mmol})$ was added to the previously prepared cold dried solution of the azide 17. Afterwards the mixture was kept $12 \mathrm{~h}$ in the refrigerator and then at room temperature for another $12 \mathrm{~h}$. The reaction mixture was washed with $0.1 \mathrm{~N} \mathrm{HCl}$, water, $5 \%$ $\mathrm{NaHCO}_{3}$ and water then dried over anhydrous sodium sulphate, the solvent was evaporated in vacuum and the residue was crystallized from ethyl acetate-petroleum ether to give 18. $2.0 \mathrm{~g}$, yield 77\%, white crystals. Mp 125-127 ${ }^{\circ} \mathrm{C}$. ${ }^{1} \mathrm{H}$ NMR spectrum, (400 MHz, $\mathrm{CDCl}_{3}$ ), $\delta$, ppm (J, Hz): 1.02 (s, 3H, $\left.\mathrm{CH}_{3}\right), 1.18\left(\mathrm{~s}, 3 \mathrm{H}, \mathrm{CH}_{3}\right), 3.4(\mathrm{bs}, 1 \mathrm{H}, \mathrm{OH})$, 4.35 (d, $\left.J=3.0 \mathrm{~Hz}, 2 \mathrm{H}, \mathrm{CH}_{2}\right), 4.60$ (s, 1H, CH), 6.08 (bs, 1H, NH), 7.10-7.28 (m, 9H, Ar-H). ${ }^{13} \mathrm{C}-\mathrm{NMR}\left(100 \mathrm{MHz}, \mathrm{CDCl}_{3}\right), \delta$, ppm: 20.7, $22.6\left(\mathrm{CH}_{3}\right), 43.6(\mathrm{C}), 46.2\left(\mathrm{CH}_{2}\right), 60.3(\mathrm{CH}), 127.7,128.0,128.3,128.8$, 129.0, 133.5, 137.8, 139.3 (C-Ar), 177.3 (CO). MS (MALDI, positive mode, matrix DHB): $m / z=340.0(\mathrm{M}+\mathrm{Na})^{+}$. Found, \%: C, 67.96; H, 6.12; $\mathrm{N}, 4.63$. For $\mathrm{C}_{18} \mathrm{H}_{20} \mathrm{ClNO}_{2}$ (317.8). Calculated, \%: C, 68.03; H, $6.34 ; \mathrm{N}, 4.41$.

\section{Antiproliferative assay}

\section{Materials and methods}

Cell cultures. A human lung cancer cell line (A549) was propagated in DMEM medium High Glucose (DMEM High Glucose w/stable Glutamine w/Sodium Pyruvate, Biowest), human breast adenocarcinoma (MCF-7), human prostate cancer (PC3), colon cancer (HCT-116), and cervical cancer (HeLa) were propagated in RPMI-1640 medium L-glutamine (Lonza Verviers SPRL, Belgium, cat\#12-604F), both medium were supplemented with $10 \%$ fetal bovine serum (FBS) (Seralab, UK, cat\# EU-000-H), and 1\% antibiotic (Antibiotic antimycotic, Biowest, cat\#). All cell lines were purchased from the American Type Culture Collection (ATCC, USA) through VACERA Co. ${ }^{19}$ The cells were incubated in $5 \% \mathrm{CO}_{2}$ humidified at $37{ }^{\circ} \mathrm{C}$ for growth.

Evaluation of cell proliferation by MTT assay. The cytotoxic effect of the tested compounds on five cancer cell lines was evaluated by the MTT (3-[4,5-methylthiazol-2-yl]-2,5-diphenyltetrazolium bromide) assay as reported previously with slight modification..$^{20,21}$ In brief, after evaluation of cell count and viability by trypan blue dye, cancer cells $\left(1 \times 10^{4}\right.$ cells per well $)$ were seeded in a 96-well plate in triplicate and were allowed to adhere for $24 \mathrm{~h}$. The tested compounds were dissolved in $500 \mu \mathrm{l}$ dimethyl sulfoxide (DMSO) to have stock solution of $100 \mathrm{mM}$, as the final concentration of DMSO in the culture medium never exceeded $0.2 \%(\mathrm{v} / \mathrm{v})^{22}$ and then various concentrations of tested compounds were prepared by further diluting in complete medium to have final concentration of $0.1,1,10$, and $100 \mu \mathrm{M}$. In the next day the medium was replaced with fresh medium with the indicated concentrations of tested compounds and cells were allowed to grow for $48 \mathrm{~h}$. Four hours before completion of incubation, $10 \mu \mathrm{l}$ of MTT ( $5 \mathrm{mg} \mathrm{mL}^{-1}$ in PBS w/o Ca, Mg, Lonza Verviers SPRL Belgium, cat\#17-516F) was added in each well. After completing the incubation, $100 \mu \mathrm{l}$ of dimethyl sulfoxide (DMSO) was added to each well, then the 96 well plates were centrifuged for 5 minutes at $4000 \mathrm{rpm}$ to precipitate the formazan crystals. Color developed after the reaction was measured at $490 \mathrm{~nm}$ using Bio-Tek microplate reader. The experiment was conducted in triplicate.

Data were calculated as percent of cell viability by the following formula: \% cell viability $=$ (mean absorbance in test wells/mean absorbance in control wells $) \times 100 .^{23}$

Molecular modeling studies. All the molecular modeling studies were carried out on Intel® ${ }^{\circledR}$ Core $^{\mathrm{TM}}$ i3 $\mathrm{CPU}, 2.40 \mathrm{GHZ}$ processor, and 3 GB memory with Windows 7 operating system 
using Molecular Operating Environment (MOE 2008-10 Chemical Computing Group, Canada) as the computational software.

For the docking studies, crystal structure of human HDAC2 complexed with an $\mathrm{N}$-(2-aminophenyl)benzamide was obtained from the freely accessible protein data bank (PDB code: $3 \mathrm{max}$ ), verification process was performed by redocking of the cocrystallized ligand into the active site using the default settings. The compounds under study were constructed 2D using ChemBio-office 2015, converted to 3D by builder interface of MOE program, and then were subjected to energy minimization with MMFF94X force and the partial charges were automatically calculated. Different conformers for each compound are imported by systematic conformational of the MOE and saved in an mdb database file to be docked into the active site of the receptor. Each complex was analyzed for interaction, 2D images were taken by using MOE visualizing tool.

\section{Conflicts of interest}

There are no conflicts to declare.

\section{Acknowledgements}

We would like to thank the Science \& Technology Development Fund in Egypt STDF Project ID: 22909 for funding this research proposal also our appreciation extended to Ass. Lect. Mohamed S. Nafie, Bioorganic Chemistry, Faculty of science, Suez Canal University for the computational chemistry work.

\section{References}

1 M. Rahman and M. R. Hasan, Metabolites, 2015, 5(4), 571.

2 Q. Wu, Z. Yang, Y. Nie, Y. Shi and D. Fan, Cancer Lett., 2014, 347, 159-166.

3 L. Gianni, G. Grasselli, S. Cresta, A. Locatelli, L. Vigano and G. Minotti, Cancer Chemother. Biol. Response Modif., 2003, 21, 29-40.

4 G. Marzaro, A. Guiotto and A. Chilin, Expert Opin. Ther. Pat., 2012, 22(3), 223.

5 S. Poorirani, S. Sadeghian-Rizi, G. Khodarahmi, M. R. Khajouei and F. Hassanzadeh, Results Pharma Sci., 2018, 13(5), 450.

6 B. D. Strahl and C. D. Allis, Nature, 2000, 403, 41-45.
7 S. E. Rundlett, A. A. Carmen, R. Kobayashi, S. Bavykin, B. M. Turner and M. Grunstein, Proc. Natl. Acad. Sci. U. S. A., 1996, 93, 14503-14508.

8 A. Petrella, B. Fontanella, A. Carratu, V. Bizzarro, M. Rodriquez and L. Parente, Mini-Rev. Med. Chem., 2011, 11, 519-527.

9 D. R. Walkinshaw and X. J. Yang, Curr. Oncol., 2008, 15(5), 237-243.

10 J. E. Bolden, M. J. Peart and R. W. Johnstone, Nat. Rev. Drug Discovery, 2006, 5, 769-784.

11 Y. Dai, Y. Guo, M. L. Curtin, J. Li, L. J. Pease, J. Guo, P. A. Marcotte, K. B. Glaser, S. K. Davidsen and M. R. Michaelides, Bioorg. Med. Chem. Lett., 2003, 13, 3817-3820.

12 D. Son, C. S. Kim, K. R. Lee and H. J. Park, Bioorg. Med. Chem. Lett., 2016, 26, 2365-2369.

13 A. P. Zorzi, M. Bernstein, Y. Samson, D. A. Wall, S. Desai, D. Nicksy, N. Wainman, E. Eisenhauer and S. Baruchel, Pediatr. Blood Cancer, 2013, 60, 1868-1874.

14 P. Atadja, Cancer Lett., 2009, 280, 233-241.

15 K. Rao-Bindal, N. V. Koshkina, J. Stewart and E. S. Kleinerman, Curr. Cancer Drug Targets, 2013, 13, 411422.

16 Y. Boumber, A. Younes and G. Garcia-Manero, Expert Opin. Invest. Drugs, 2011, 20, 823-829.

17 R. H. Kalita, A. J. Borah and P. Phukan, Indian J. Chem., 2013, 52(B), 289.

18 F. Fringuelli, D. Lanari, F. Pizzo and L. Vaccaro, Green Chem., 2010, 12, 1301.

19 D. S. El-Kady, A. A. Abd Rabou, M. A. Tantawy, A. A.-H. AbdelRahman, A. A.-S. Abdel-Megeed, M. M. AbdElhalim and G. A. Elmegeed, Appl. Biochem. Biotechnol., 2019, DOI: 10.1007/s12010-018-02943-6.

20 D. K. Maurya, N. Nandakumar and T. P. Devasagayam, J. Clin. Biochem. Nutr., 2011, 48(1), 85.

21 A. A.-H. Sebeka, A. M. A. Osman, I. E.-T. El Sayed, M. El Bahanasawy and M. A. Tantawy, J. Appl. Pharm. Sci., 2017, 7(10), 9.

22 S. Ranganathan, D. Halagowder and N. D. Sivasithambaram, PLoS One, 2015, 10(10), e0141370.

23 M. A. Tantawy, M. S. Nafie, G. A. Elmegeed and I. A. I. Ali, Bioorg. Chem., 2017, 73, 128-146. 